\title{
Enhanced IFN- $\gamma$, but not IL-2, response to Mycobacterium tuberculosis antigens in HIV/ latent TB co-infected patients on long-term HAART
}

Girmay Desalegn ${ }^{1,2,3^{*}}$ D, Aster Tsegaye ${ }^{2}$, Dawit Gebreegziabiher ${ }^{1,3}$, Abraham Aseffa $^{1}$ and Rawleigh Howe ${ }^{1}$

\begin{abstract}
Background: HIV-infected individuals with latent TB infection are at increased risk of developing active TB. HAART greatly reduces the incidence rate of TB in HIV-infected patients and reconstitutes Mycobacterium tuberculosis ( $M$. tuberculosis)-specific immune response in the first 12 months of therapy. The durability of the anti-mycobacterial immune restoration after a year of HAART however remains less investigated.

Method: A cross-sectional study was conducted to evaluate M. tuberculosis-specific functional immune responses in HIV/latent TB co-infected patients who were on HAART for at least 1.5 up to 9 years as compared to HAART-naïve patients. Three-hundred sixteen HIV-infected patients without active TB were screened by tuberculin skin testing for M. tuberculosis infection and peripheral blood mononuclear cells (PBMCs) were isolated from $61 \mathrm{HIV/latent} \mathrm{TB} \mathrm{cO-}$ infected patients (30 HAART-naïve and 31 HAART-treated). IFN- $\gamma$ and IL-2 ELISPOT as well as CFSE cell proliferation assays were performed after stimulation with M. tuberculosis antigens PPD and ESAT-6.

Result: The median frequency of PPD and ESAT-6 specific IFN- $-\gamma$ secreting cells was significantly higher in the HAART-treated patients as compared to HAART-naive patients, $p=0.0021$ and $p=0.0081$ respectively. However, there was no significant difference in the median frequency of IL-2 secreting cells responding to PPD $(p=0.5981)$ and ESAT-6 $(p=0.3943)$ antigens between HAART-naïve and-treated groups. Both IFN- $\gamma$ and IL-2 responses were independent of $\mathrm{CD}^{+} \mathrm{T}$ cell count regardless of the HAART status. Notably, the frequency of PPD and ESAT-6 specific IL-2 secreting cells was positively associated with $C D 4^{+} T$ cell proliferation while inversely correlated with duration of HAART, raising the possibility that $M$. tuberculosis-specific IL-2 response that promote the antigenspecific CD4 ${ }^{+} \mathrm{T}$ cell proliferation diminish with time on antiretroviral therapy in HIV/latent TB co-infected patients.

Conclusion: This study shows an increased M. tuberculosis-specific IFN- $\gamma$, but not IL-2, response in HIV/latent TB coinfected patients with long-term HAART, consistent with only partial immune restoration. Future studies should, therefore, be done to prospectively define the rate and extent to which functional immune responses to $M$. tuberculosis are restored after long-term HAART.
\end{abstract}

Keywords: HIV, HAART, Latent TB infection, M. Tuberculosis, IFN- $\gamma$, IL-2, CD4 ${ }^{+}$T cells

\footnotetext{
* Correspondence: gdesalegn2@gmail.com

${ }^{1}$ Armauer Hansen Research Institute, Addis Ababa, Ethiopia

${ }^{2}$ Department of Medical Laboratory Sciences, Addis Ababa University, Addis

Ababa, Ethiopia

Full list of author information is available at the end of the article
}

(c) The Author(s). 2019 Open Access This article is distributed under the terms of the Creative Commons Attribution 4.0 International License (http://creativecommons.org/licenses/by/4.0/), which permits unrestricted use, distribution, and reproduction in any medium, provided you give appropriate credit to the original author(s) and the source, provide a link to the Creative Commons license, and indicate if changes were made. The Creative Commons Public Domain Dedication waiver (http://creativecommons.org/publicdomain/zero/1.0/) applies to the data made available in this article, unless otherwise stated. 


\section{Background}

Tuberculosis (TB) is the one of the leading deadly diseases worldwide with over $90 \%$ of deaths occurring in developing countries [1]. TB is caused by direct exposure to Mycobacterium tuberculosis (M. tuberculosis), and/or reactivation of latent TB infection. Once infected with $M$. tuberculosis, only about $5-10 \%$ of people directly develop active TB while 90-95\% remain latently infected [2, 3]. In 2014, approximately 1.7 billion people were latently infected with $M$. tuberculosis globally, lowand middle-income countries accounting for around $80 \%$ of the prevalence [4]. Immunocompetent individuals control the infection by containing the mycobacteria in an inactive or latent state. Both the innate and adaptive arms of the immune system are involved in a collaborative way to control infection with $M$. tuberculosis and subsequent disease. Various $\mathrm{T}$ cells produce potent cytokines and the interaction of these cells with infected macrophages are crucial for anti-mycobacterial protective responses [2, 3, 5-7]. People with latent TB infection have only $5-10 \%$ lifetime risk of reactivation [8]. However, following acquisition of HIV infection, the risk of reactivation of latent $\mathrm{TB}$ infection to active $\mathrm{TB}$ increases to $5-10 \%$ each year $[3,9]$. This high rate of active TB development might be directly related to HIVderived weakened host cell-mediated immunity in general, and impaired $M$. tuberculosis-specific immune responses in particular. M. tuberculosis-specific production of interferon-(IFN)- $\gamma$, interleukin (IL)-2 and Tumor necrosis factor (TNF)- $\alpha$ by $\mathrm{T}$ cells contribute substantially to elicit effective immunity to prevent reactivation of latent TB infection [7, 10-12].

Highly active anti-retroviral therapy (HAART) reduces the incidence rate of TB in people living with HIV. A meta-analysis of various studies has shown that HAART is associated with a $67 \%$ reduction (range: $61-73 \%$ ) in TB incidence [13-16]. Reduction of TB incidence rate after initiation of HAART could likely be due to continuous $\mathrm{CD}^{+} \mathrm{T}$ cell recovery $[14,17]$ accompanied by restoration of functional anti-mycobacterial immunity. This is supported by studies which demonstrated initiation of HAART leads to rapid functional recovery of mycobacteria-specific immune responses, with increasing lymphocyte proliferation and secretion of IFN- $\gamma$ by peripheral blood mononuclear cells (PBMCs) stimulated ex vivo with mycobacterial antigens [18-20]. However, most investigators have evaluated responses within 1 year of HAART initiation. Immune reconstitution occurs in two or more phases over time. $\mathrm{CD}^{+} \mathrm{T}$ cells recovery observed in the first year of HAART is rapid and prominent, and primarily a result of an immediate redistribution of memory CD4 ${ }^{+} \mathrm{T}$-cells from the lymphoid tissues into the blood streams [21-23]. After a year of therapy, this phase is followed by a slow recovery of $\mathrm{CD}^{+} \mathrm{T}$ - cells and is mainly due to de novo production of new naïve $\mathrm{T}$ lymphocytes and reduced apoptosis [22, 24, 25]. Thus, the former process could explain enhanced immune reactivity to $M$. tuberculosis observed in the previous studies within the first year of HAART. In contrast, the functional immune response to $M$. tuberculosis in HIV/latent TB co-infected patients after prolonged HAART therapy has not been well studied. As a result, questions still remain regarding the extent and nature of the anti-mycobacterial immune reconstitution in the long-term of HAART. We therefore aimed at investigating the durability of HAART-driven anti-mycobacterial immune responses with the hypothesis that long-term HAART would still augment protective immune responses against M. tuberculosis in HIV/latent TB coinfected patients. In this study we observed an increased, but only partly, $M$. tuberculosis-specific functional immune responses in $\mathrm{HIV} /$ latent $\mathrm{TB}$ co-infected patients who received HAART for more than a year as compared to HAART-naïve patients.

\section{Methods \\ Study participants}

The recruitment and enrollment of participants in this study is summarized in Fig. 1. HIV-infected patients were consecutively selected by their attending clinicians in ALERT hospital, Addis Ababa, Ethiopia from July 2011 to January 2012. Participants with active TB, active hepatitis, pregnancy, history of close contact with multidrug-resistant TB patients and prior Bacille Calmette-Guérin (BCG) vaccination within the previous 10 years were excluded from recruitment in this study. The exclusion of the relatively recent BCG vaccinated recipients was done to minimize impact of BCG on TST responses. Three hundred sixteen HIV positive patients were screened with the tuberculin skin test (TST) by administering $0.1 \mathrm{ml}$ of the 2-TU PPD, RT23 (Statens Serum Institute (SSI), Denmark) intradermally. The transverse diameter of induration was measured after 48-72 $\mathrm{h}$ and the TST response was considered positive when the induration was $>5 \mathrm{~mm}[26,27]$. Of the 316 participants, only 61 were positive for TST and later confirmed by IFN- $\gamma$ enzyme-linked immunospot (ELISPOT) to be latently infected with $M$. tuberculosis. Of these 61 participants, 30 were HAART-naïve and 31 received HAART for at least 1.5 up to 9 years, and were included in this cross-sectional study to evaluate $M$. tuberculosis-specific functional immune responses in HIV/ latent $\mathrm{TB}$ co-infected patients with and without longterm HAART. As per then existing policy of the Ministry of Health of Ethiopia, all HAART-treated HIV positive individuals were presumably put on HAART when their $\mathrm{CD}^{+} \mathrm{T}$ cell counts were 200 cells/ $\mu \mathrm{l}$ or less. 


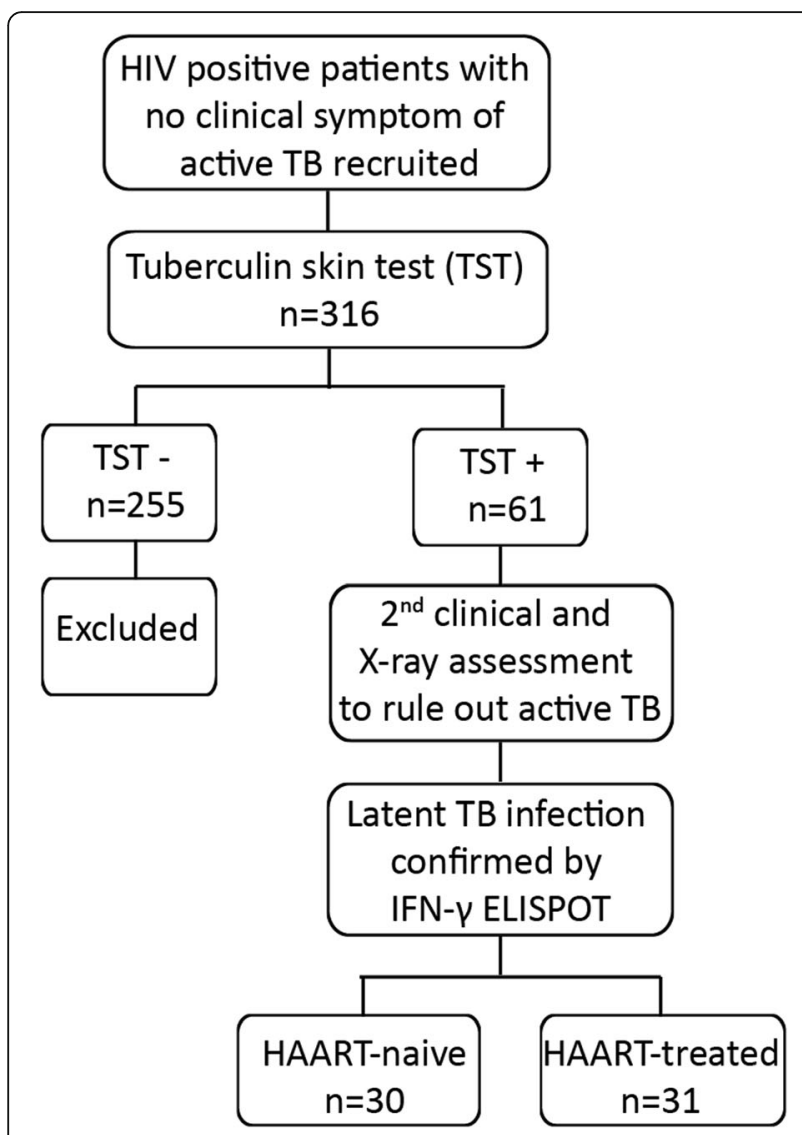

Fig. 1 Flow chart of the recruitment and enrollment of participants in this study

Blood collection for $\mathrm{CD}^{+} \mathrm{T}$ cell count and PBMC isolation Heparinized blood samples were collected from all study participants. $\mathrm{CD}^{+} \mathrm{T}$ cell count was determined by a Becton Dickinson (BD) FACSCount flow cytometer (BD Biosciences, USA) and PBMCs were also isolated by means of Ficoll-Paque PLUS ${ }^{\mathrm{TM}}$ (GE Healthcare Biosciences AB, Sweden) density centrifugation using Leucosep tubes (Greiner Bio-One B. V, Netherlands). PBMCs were stored until analysis at $-80^{\circ} \mathrm{C}$ at a $5-10 \times 10^{6} \mathrm{cells} / \mathrm{ml} /$ vial in freezing media (10\% Dimethyl sulfoxide (DMSO) and 90\% Fetal Bovine Serum (FBS)) (Sigma-Aldrich Co, USA). When required, PBMCs were then thawed and re-suspended in RPMI 1640 supplemented with 1\% Penicillin/Streptomycin, 1\% L-Glutamine (Sigma-Aldrich Chemie GmbH, Germany) and 10\% FBS (Sigma-Aldrich Co, USA).

\section{Ex vivo IFN- $\gamma$ and IL-2 ELISPOT}

Human IFN- $\gamma$ and IL-2 ELISPOT kits (Mabtech AB, Sweden) were used to determine the frequency of IFN- $\gamma$ and IL-2 secreting cells in response to $M$. tuberculosis antigens and were performed according to the manufacturer's protocol and as described before [28]. Plates were seeded with $2 \times$ $10^{5}$ PBMCs/well in duplicate in the presence of PPD, ESAT-
6 (SSI, Denmark), anti-CD3 (positive control; Mabtech AB, Sweden) or left unstimulated (negative control). The final concentration of $5 \mu \mathrm{g} / \mathrm{ml}$ for PPD and ESAT-6, and 1:1000 dilution for anti-CD3 were used. The numbers of spot forming cells (SFCs) in respective wells were quantified using an automated ELISPOT plate reader (Autoimmun Diagnostika (AID), Germany). The intensity and size of the spots were predefined and the same setting was used throughout. The average SFC counts of the duplicate wells were calculated and the final number of antigen specific SFCs were determined by subtracting media background spots from those of stimulant containing wells. To reveal the validity of the test results, ELISPOT response was predefined to be at least $750 \mathrm{SFCs} / 10^{6} \mathrm{PBMCs}$ in the anti-CD3 positive control wells [29] and all results were valid. A positive IFN- $\gamma$ response to $M$. tuberculosis antigen was taken as more than 50 SFCs $/ 10^{6} \mathrm{PBMCs}$ after negative control well SFC subtraction $[29,30]$.

\section{T cell proliferation assay}

Cell proliferation was determined by the carboxyfluorescein diacetate succinimidyl ester (CFSE) dilution assay using the CellTrace ${ }^{\mathrm{sm}}$ CFSE Cell Proliferation Kit (Invitrogen, USA) and was performed according to the manufacturer's protocol. $2 \times 10^{6}$ PBMCs were stained with final concentration of $0.3 \mu \mathrm{M}$ CFSE prior to culture. Then, $1.5 \times 10^{5}$ cells were cultured in a 96-wells plate in duplicate in the presence of PHA (positive control; Sigma-Aldrich Chemie GmbH, Germany), PPD and ESAT-6 (SSI) or left unstimulated (negative control) at $37^{\circ} \mathrm{C}$ in a $5 \% \mathrm{CO}_{2}$ humidified incubator. The final concentration of each antigens were $5 \mu \mathrm{g} / \mathrm{ml}$. After 4 days (PHA) and 6 days (other conditions), the cells were harvested and stained with anti-CD3-APC, anti-CD4-PeCy5 and anti-CD8-PE (BD Biosciences). Cells were acquired by a FACSCanto II flow cytometer and data were analyzed by FlowJo (TreeStar, USA). Proliferating cells were defined as those with reduced (low or dim) CFSE expression and \% specific proliferation defined as the fraction of cells with low CFSE after subtraction of unstimulated control cell values.

\section{Statistical analysis}

Data were entered, cleaned and analyzed using SPSS version 15.0 and Graph pad Prism version 6.01 softwares. The normality of the data was evaluated by both Kolmogorov-Smirnov test and D'Agostino-Pearson normality test, and none of the continuous variables were Gaussian even after normalization. Thus, the frequencies of IFN- $\gamma$ and IL-2 secreting cells responding to $M$. tuberculosis antigens between HAART-naïve and-treated groups were compared using a non-parametric Mann-Whitney test. Data are 
shown as median with interquartile range (IQR). Spearman correlation test was also used to demonstrate the association between two continuous variables. $P<0.05$ were considered statistically significant.

\section{Results}

\section{Demographic and clinical information}

Sixty-one HIV-infected patients with latent TB infection were enrolled for the purpose this study and of these, 30 were HAART-naïve and 31 received HAART for more than a year. The majority, 49/61 (80.3\%), of the enrolled participants were females and of these, 24 (49\%) were HAART-naïve and 25 (51\%) received HAART. The duration of therapy in the HAART-treated group ranged from 1.5 to 9 years with a median of 3 years (IQR 2.5-5). The median age of the participants was 32 years (IQR $29-40)$ with the highest proportion $(24 / 61,39 \%)$ in the age range of $30-39$, of which $13 / 24$ and $11 / 24$ were HAART-naïve and HAART-treated respectively. Education wise, $39.3 \%(24 / 61)$ of the study participants had a primary level of education and $31.1 \%(19 / 61)$ were illiterate. The majority of participants, 60.7\% (37/61) were married while $41.0 \%(25 / 61)$ were private workers and $36.1 \%(22 / 61)$ were housewives. In addition, hierarchal multiple regression analysis was performed to assess the association between demographic characteristics and antigen-specific IFN- $\gamma$ and IL-2 responses. We observed that there were no statistical significant association between the demographic characteristics (age, gender, occupation, educational level, marital status) of the study participants, and the frequency of IFN- $\gamma$ and IL-2 secreting cells irrespective of the stimuli antigen.

Thirteen participants $(21.3 \%)$ had previously been vaccinated with BCG at childhood; of these, 2/13 (15.4\%) were HAART-naïve and 11/13 (84.6\%) HAART treated participants (Table 1). In addition, according to their hospital follow-up records, only 6 (5 HAART-naïve and 1 HAART-treated) had infections within 3 months of recruitment to this study. Upper respiratory tract Infections, urinary tract infections and sexually transmitted infections were the infections documented in the charts of these study participants.

\section{$\mathrm{CD4}^{+} \mathrm{T}$ cell count}

We determined the $\mathrm{CD}^{+} \mathrm{T}$ cell count of enrolled participants as shown in Table 1. All study participants had $\mathrm{CD}^{+}{ }^{+} \mathrm{T}$ cell counts greater than $200 / \mu \mathrm{l}$ with the overall median count of $477 / \mu \mathrm{l}$ (IQR 367-567). $\mathrm{CD}^{+}{ }^{+}$T-cell count of HAART-treated participants was relatively higher than HAART-naïve group with a median count of 502/ $\mu \mathrm{l}$ (IQR 363-564) and 445/ $\mu \mathrm{l}$ (IQR 371-626) respectively, though these differences did not reach statistical significance, $p=0.9368$. Nevertheless, we observed that HAART-treated participants considerably gained $\mathrm{CD} 4^{+} \mathrm{T}$ cells years after therapy (Additional file 3: Figure S3a). Based on the $\mathrm{CD}_{4}^{+} \mathrm{T}$ cell count, study partici-

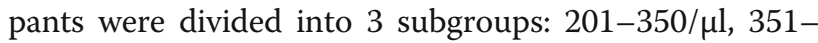
$500 / \mu \mathrm{l}$ and $>500 / \mu \mathrm{l}$. Of the total participants, $29(47.5 \%)$ and $21(34.4 \%)$ had a CD4 ${ }^{+}$T-cells of $>500 / \mu \mathrm{l}$ and $351-$ $500 / \mu$ respectively. $43.3 \%(13 / 30)$ and $51.6 \%(16 / 31)$ of HAART-naïve and HAART-treated participants respectively had a CD $4^{+} \mathrm{T}$-cell count of $>500$ cells/ $\mu$.

\section{Frequency of IFN- $\gamma$ secreting cells in response to $M$. tuberculosis antigens}

PPD and ESAT-6 specific IFN- $\gamma$ responses were assessed in participants who received HAART for at least 1.5 years in comparison with those who were HAARTnaïve. As shown in Fig. 2a, the median frequency of PPD-specific IFN- $\gamma$ producing cells was significantly higher in HAART-treated participants (580 SFCs/ $10^{6}$ PBMCs, IQR $\left.365-2205\right)$ as compared to the pre-

Table 1 Clinical and laboratory data of the study participants $(n=61)$

\begin{tabular}{|c|c|c|c|}
\hline \multirow[t]{2}{*}{ Variable } & \multicolumn{3}{|c|}{ №. (\%) HIV/latent TB co-infected participants } \\
\hline & $\begin{array}{l}\text { HAART-naïve } \\
n=30\end{array}$ & $\begin{array}{l}\text { HAART-treated } \\
n=31\end{array}$ & $\begin{array}{l}\text { Total } \\
n=61\end{array}$ \\
\hline $\mathrm{CD}^{+}$count (cells/Ml), Median (IQR) & $445(371-626)$ & $502(363-564)$ & $477(367-567)$ \\
\hline $201-350$ & $7(23.3)$ & $4(12.9)$ & $11(18.0)$ \\
\hline $351-500$ & $10(33.3)$ & $11(35.5)$ & $21(34.4)$ \\
\hline$>500$ & $13(43.3)$ & $16(51.6)$ & $29(47.5)$ \\
\hline \multicolumn{4}{|l|}{${ }^{a}$ History of Previous BCG Vaccination } \\
\hline Yes & $2(6.7)$ & $11(35.5)$ & $13(21.3)$ \\
\hline No & $28(93.3)$ & $20(64.5)$ & $48(78.7)$ \\
\hline \multicolumn{4}{|l|}{${ }^{b}$ Recent infections } \\
\hline Present & $5(16.7)$ & $1(3.2)$ & $6(9.8)$ \\
\hline Absent & 25 (83.3) & $30(96.8)$ & $55(90.2)$ \\
\hline
\end{tabular}

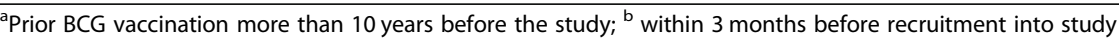




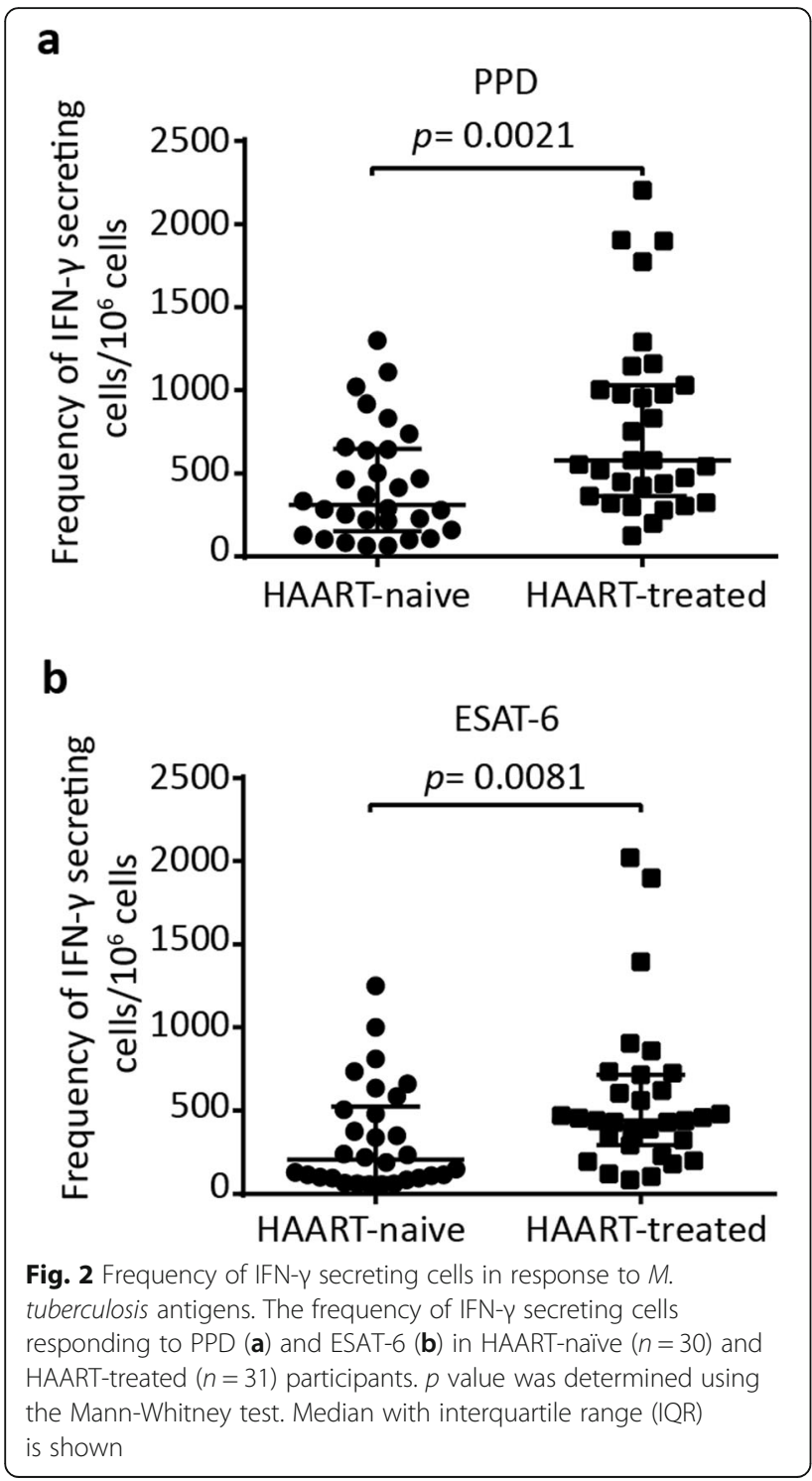

HAART participants (313 SFCs $/ 10^{6} \mathrm{PBMCs}$, IQR $153-$ 1300), $p=0.0021$. In addition, the median frequency of IFN- $\gamma$ secreting cells in response to ESAT-6 was also significantly higher in the HAART-treated group (440 SFCs $/ 10^{6}$ PBMCs, IQR 295-2020) than HAART-naive subjects (205 SFCs $/ 10^{6} \mathrm{PBMCs}$, IQR 95-1250), $p=$ 0.0081 (Fig. 2b). We then used spearman correlation analysis to determine whether $M$. tuberculosis-specific IFN- $\gamma$ responses are associated with $\mathrm{CD}^{+} \mathrm{T}$ cell count of the patients. Regardless of HAART status, $\mathrm{CD}^{+}{ }^{+} \mathrm{T}$ cell counts were not significantly correlated with the frequency IFN- $\gamma$ secreting cells responding to PPD and ESAT-6 (Additional file 1: Figure S1). This data demonstrates an increased M. tuberculosisspecific IFN- $\gamma$ response in $\mathrm{HIV} /$ latent $\mathrm{TB}$ co-infected patients with long-term HAART irrespective of the $\mathrm{CD} 4^{+} \mathrm{T}$ cell count.
Frequency of IL-2 secreting cells in response to $M$. tuberculosis antigens

We then quantified the frequencies of IL-2-secreting cells responding to PPD and ESAT-6 to determine the effect of anti-retroviral treatment on the $M$. tuberculosis antigen-specific IL-2 response. There was no significant difference in the IL-2 response to PPD between HAART-naïve (median 95 SFCs $/ 10^{6}$ PBMCs, IQR 30183 ) and HAART-treated (median $85 \mathrm{SFCs} / 10^{6} \mathrm{PBMCs}$, IQR 60-240) groups, $p=0.5981$ (Fig. 3a). Similarly, ESAT-6 elicited IL-2 responses did not differ significantly between HAART-naïve (median 30 SFCs/ $10^{6}$ PBMCs, IQR 14-103) and HAART-treated (median 55 SFCs $/ 10^{6}$ PBMCs, IQR $\left.15-120\right)$ subjects, $p=0.3943$ (Fig. 3b). Similar to the IFN- $\gamma$ responses, there was no statistically significant correlation between $\mathrm{CD}^{+} \mathrm{T}$ cell count and the frequencies of IL-2 secreting cells responding to PPD or ESAT-6 irrespective of anti-

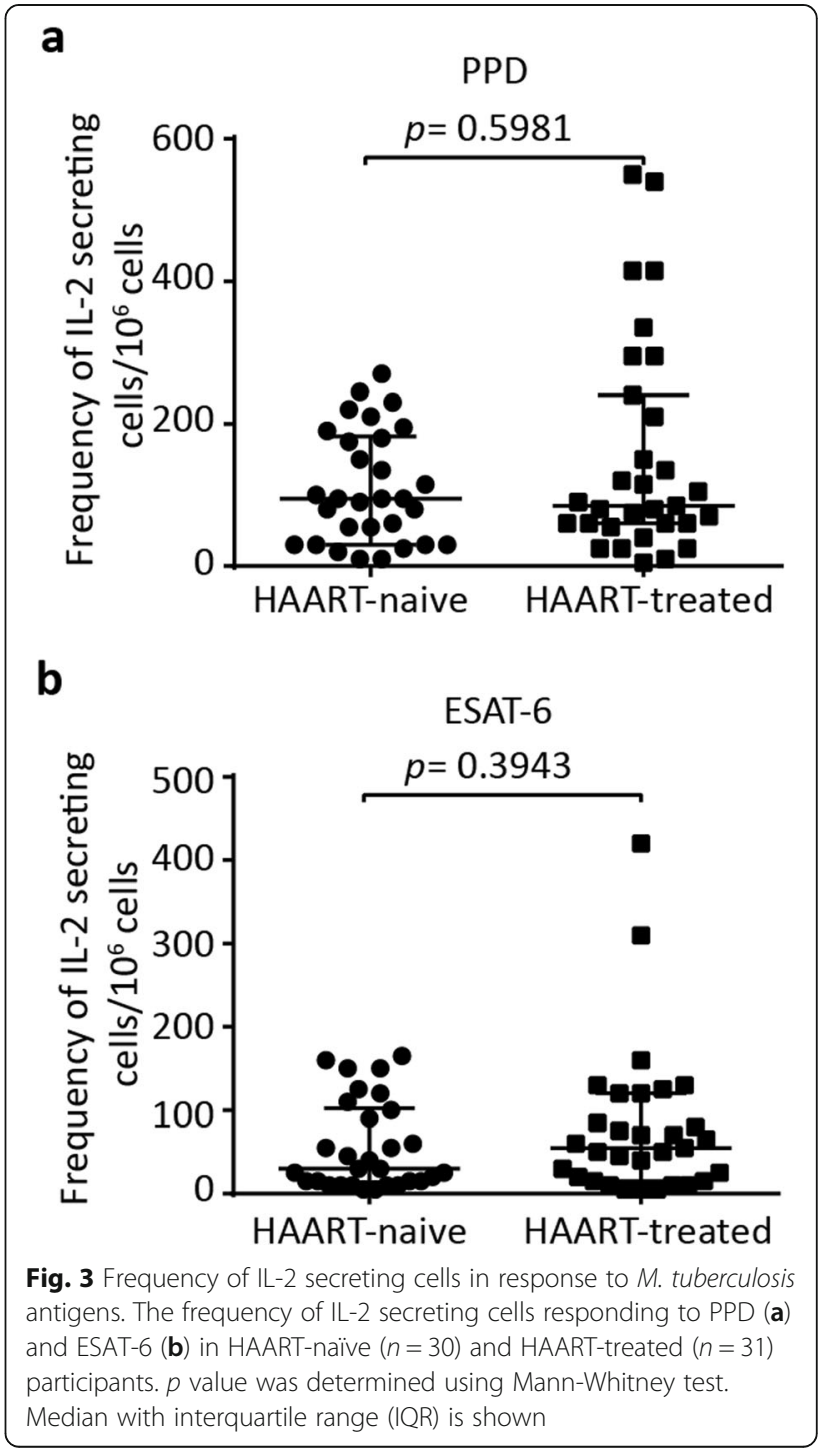


retroviral treatment (Additional file 2: Figure S2). This shows that $M$. tuberculosis-specific IL-2 response was not enhanced during the long-term HAART therapy regardless of the $\mathrm{CD} 4^{+} \mathrm{T}$ cell count.

\section{Correlation of IFN- $\gamma$ and IL-2 responses specific to $M$. tuberculosis antigens}

Correlation between the $M$. tuberculosis antigen-specific frequencies of IFN- $\gamma$ and IL-2-secreting cells was assessed. In pre-HAART patients (Fig. 4a), we found a statistically significant correlation between PPD-specific frequencies of IFN- $\gamma$ and IL-2 secreting cells $\left(\mathrm{r}_{\mathrm{s}}=\right.$ $0.3934, p=0.0315$ ) and a modest though not statistically significant correlation in the ESAT- 6 stimulated cells $\left(\mathrm{r}_{\mathrm{s}}=0.3005, p=0.1066\right)$. In contrast, the IFN- $\gamma$ and IL-2 responses were unrelated when elicited to either PPD $\left(\mathrm{r}_{\mathrm{s}}=0.1592, p=0.3924\right)$ or ESAT-6 $\left(\mathrm{r}_{\mathrm{s}}=0.1208, p=\right.$ 0.5173 ) in the HAART-treated group (Fig. 4b). Thus, the absence of correlation between $M$. tuberculosis-specific IFN- $\gamma$ and IL- 2 productions in the HAART-treated participants suggest that these cytokines could be secreted by different $\mathrm{T}$ cell subsets in patients on therapy.
Correlation of $M$. tuberculosis antigen-specific cytokine responses and duration of HAART

We then assessed whether IFN- $\gamma$ and IL-2 responses specific to $M$. tuberculosis antigens were associated with duration of HAART. No association was observed between duration of HAART and IFN- $\gamma$ production responding to PPD $\left(\mathrm{r}_{\mathrm{s}}=-0.1842, p=0.3214\right)$ or ESAT-6 $\left(r_{\mathrm{s}}=-0.1622, p=0.3834\right)$ (Fig. 5a), nor were there correlations between therapy duration and IFN- $\gamma / \mathrm{IL}-2$ ratios to PPD $\left(\mathrm{r}_{\mathrm{s}}=0.2466, p=0.1812\right)$ or ESAT-6 $\left(\mathrm{r}_{\mathrm{s}}=0.2568\right.$, $p=0.1632$ ) (data not shown). Importantly and in stark contrast, we observed that $M$. tuberculosis-specific IL-2 responses negatively correlated with duration on antiretroviral therapy; this relation was apparent for both ESAT-6 $\left(\mathrm{r}_{\mathrm{s}}=-0.4359, p=0.0142\right)$ and PPD $\left(\mathrm{r}_{\mathrm{s}}=-\right.$ 0.3450, $p=0.0573$ ) (Fig. 5b).

We considered the possibility that this finding might be explained by a drop in IL-2 responses related to a loss in $\mathrm{CD}^{+} \mathrm{T}$ cells in some patients on prolonged HAART after initial gains. Such a possibility would predict a positive correlation between net $\mathrm{CD}^{+}{ }^{+} \mathrm{T}$ cell gain after therapy and IL-2 production. The number of $\mathrm{CD}^{+}{ }^{+} \mathrm{T}$ cells gained after HAART was positively associated with

\section{a}

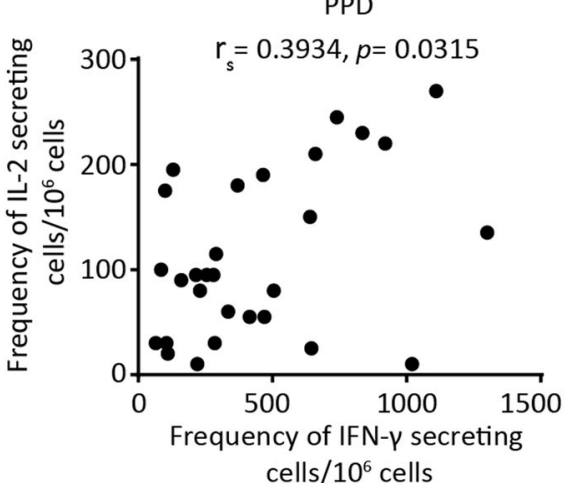

b

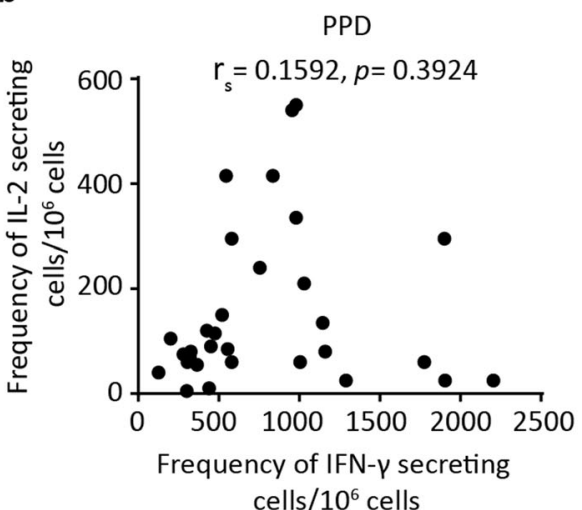

ESAT-6

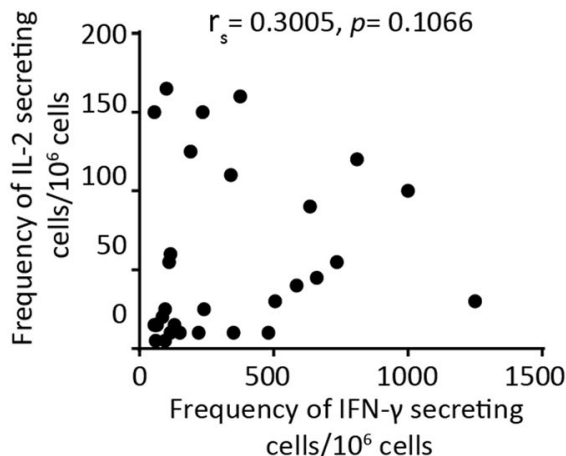

ESAT-6

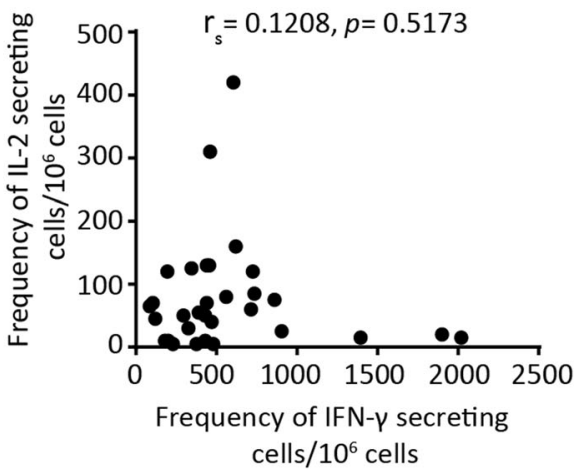

Fig. 4 Correlation of IFN- $\gamma$ and IL-2 responses specific to M. tuberculosis antigens. Correlation between the frequency PPD and ESAT-6 specific IFN- $\gamma$ and IL-2 secreting cells in HAART-naïve $(\mathbf{a}, n=30)$ and HAART-treated $(\mathbf{b}, n=31)$ participants. Spearman correlation was used to calculate correlation coefficients $\left(r_{s}\right)$ and $p$ values 

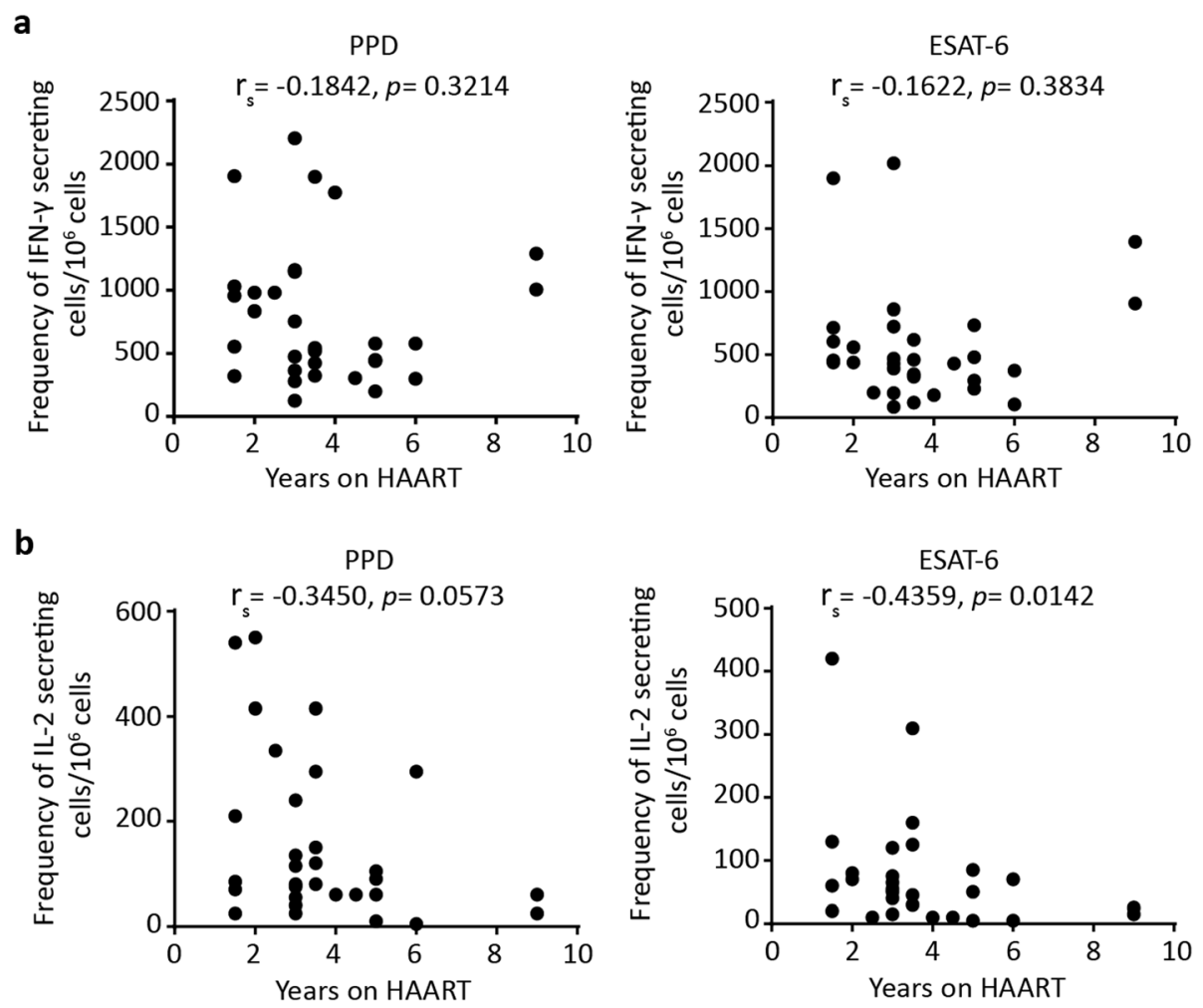

Fig. 5 Correlation of M. tuberculosis antigen-specific cytokine responses and duration of HAART. The correlation between PPD and ESAT-6 specific frequency of IFN- $\gamma(\mathbf{a})$ and IL-2 (b) secreting cells and duration of HAART among the HAART-treated participants $(n=31)$. Spearman correlation was used to calculate correlation coefficients $\left(r_{s}\right)$ and $p$ values

therapy duration (Additional file 3: Figure S3b). However, as depicted in the Additional file 3: Figure S3c and $\mathrm{d}$, neither IL-2 nor IFN- $\gamma$ secreting cell frequencies were related to $\mathrm{CD} 4^{+} \mathrm{T}$ cell gain. Collectively, these results indicate that it is HAART duration but not $\mathrm{CD}^{+}{ }^{+} \mathrm{T}$ cell count nor $\mathrm{CD}_{4}^{+} \mathrm{T}$ cell gain which predicted decreased M. tuberculosis-specific IL-2 responses. In contrast, no such correlation was observed with HAART duration and IFN- $\gamma$ responses.

\section{Association of IL-2 production and T cell proliferation in response to $M$. tuberculosis antigens}

IL-2 is a growth factor that promotes proliferation of the antigen specific $T$ cells $[11,31]$. To assess whether IL-2 production was associated with $\mathrm{T}$ cell proliferative capacity, we performed in vitro proliferation assays on a limited number of participants selected regardless of their HAART therapy. The proliferative capacity of the $\mathrm{T}$ cells and $\mathrm{CD} 4^{+} \mathrm{T}$ cells among the total PBMCs were assessed by flow cytometry using the gating strategy shown in Fig. 6a. We found no statistically significant association between the frequencies of IL-2 secreting cells and proliferating T cells in response to PPD $\left(\mathrm{r}_{\mathrm{s}}=0.3333\right.$, $p=0.3853)$ and ESAT-6 $\left(\mathrm{r}_{\mathrm{s}}=0.5758 p=0.0883\right)$ (Additional file 4: Figure S4). However, after gating on $\mathrm{CD}^{+}$
$\mathrm{T}$ cells, CFSE dim proliferating $\mathrm{CD} 4^{+} \mathrm{T}$ cells were positively correlated with the frequencies of IL-2 secreting cells with PPD $\left(\mathrm{r}_{\mathrm{s}}=0.8333, p=0.0083\right)$ and ESAT- $6\left(\mathrm{r}_{\mathrm{s}}=\right.$ $0.7818, p=0.0105$ ) stimulation (Fig. $6 \mathrm{~b}$ ). This confirms that $M$. tuberculosis-specific IL-2 response is highly correlated with the mycobacteria-specific $\mathrm{CD}_{4}^{+} \mathrm{T}$ cell proliferation in HIV/latent TB co-infected patients.

\section{Discussion}

The incidence rate of TB in HIV-infected patients who initiate HAART is significantly decreased compared to patients without therapy, but even on antiretroviral therapy, the risk for TB is higher than HIV uninfected individuals $[14,32]$. Clarification of the quality and quantity of the incomplete immune recovery and developing means to improve clinical outcomes thus remain an important priority in the HIV field. HAART-driven immune restoration is thought to occur in two phases; the first and fast phase is due to immediate redistribution of memory $\mathrm{CD} 4^{+}$ $\mathrm{T}$ cells from lymphoid tissues to peripheral blood, but does not involve significant net changes in $\mathrm{CD}^{+} \mathrm{T}$ cell number, followed by slow gradual immune recovery as a result of de novo production of naïve or memory $\mathrm{T}$ lymphocytes and reduced apoptosis [21-25, 33, 34]. Most studies that have assessed restoration of $M$. tuberculosis- 
a

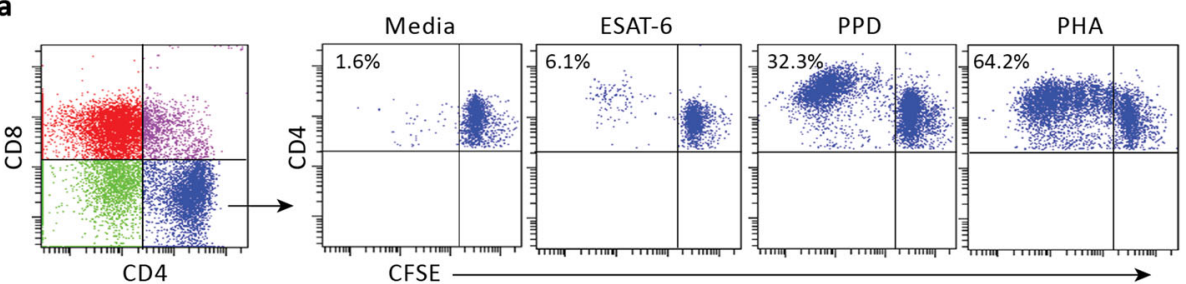

b
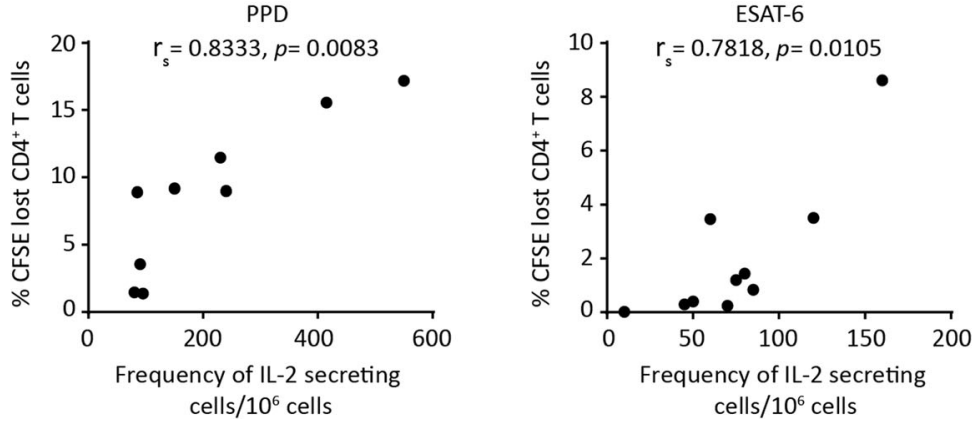

Fig. 6 Association of IL-2 production and $C D 4^{+} T$ cell proliferation in response to M. tuberculosis antigens. a The gating strategy for CFSE lost proliferating $\mathrm{CD}^{+}{ }^{+} \mathrm{T}$ cells in the Media (unstimulated control), ESAT-6, PPD and PHA (positive control) stimulated cells. Numbers indicate the percentage CFST lost cells among the CD4 ${ }^{+} T$ cells. $\mathbf{b}$ Correlation between frequency of IL-2-secreting cells and proliferating CD4 ${ }^{+} T$ cells among total PBMCs after stimulation with PPD $(n=9)$ and ESAT-6 $(n=10)$. Spearman correlation was used to calculate correlation coefficients $\left(r_{s}\right)$ and $p$ values

specific responses have typically involved cohort studies evaluating immune reconstitution before and after up to one year of therapy, which would be predicted to address changes primarily due to the fast redistribution phase. We carried out this cross-sectional study to enumerate TBspecific immune responses among patients without HAART and with a range of duration on therapy from 1.5 up to 9 years. We found that PPD and ESAT-6-specific IFN- $\gamma$ responses were significantly higher in HIV-infected patients who received HAART for more than a year compared to the pre-HAART participants, consistent with the observations of cohort studies evaluating responses within the first 6 to 12 months of HAART [18, 35, 36]. Hence, this shows that anti-mycobacterial IFN- $\gamma$ responses are restored after initiation of HAART and maintained for prolonged period of the therapy. In contrast to the IFN- $\gamma$ response, however there was no significant difference between HAART-naive and-treated patients in $M$. tuberculosis-specific IL-2 production. These results contrast with studies done on patient cohorts with less than one year of HAART $[37,38]$. Notably, we observed that $M$. tuberculosis-specific IL-2 responses were inversely correlated with duration of HAART, and not related to either $\mathrm{CD}^{+}{ }^{+} \mathrm{T}$ cell count or $\mathrm{CD} 4^{+}$ $\mathrm{T}$ cell gain after HAART. These findings raise the possibility that IL-2 responses may be restored only transiently during the initial redistribution phase, which would accommodate previous studies, but are unable to be maintained during long-term antiretroviral therapy in the secondary phase.

$\mathrm{T}$ cell subpopulations including $\mathrm{CD} 4^{+}$and $\mathrm{CD} 8^{+} \mathrm{T}$ cells are known to produce IFN- $\gamma$ and/or IL-2. These T cells can be divided into distinct populations of effector cells, effector memory and central memory cells [39]. Effector T cells show immediate effector function of secreting IFN- $\gamma$ whereas effector memory $\mathrm{T}$ cells produces both IFN- $\gamma$ and IL-2 cytokines [40, 41], but in advanced HIV disease tend to produce relatively more IFN- $\gamma[42,43]$. On the other hand, central memory $\mathrm{T}$ cells typically produce predominantly IL-2 [40, 41]. Presumably the differences we observed in IL-2 responses between the relatively early HAART and prolonged HAART reflect differences in the frequencies of these $\mathrm{T}$ cells subsets. However, since our studies were done on unfractionated cells, we could not enumerate the relative contribution of these subsets, nor the frequency of IFN- $\gamma / \mathrm{IL}-2$ co-producing cells which may have impacted the observed results. Nonetheless, the fact that we did not observe correlations between the cytokine producing cells and $\mathrm{CD}_{4}^{+} \mathrm{T}$ cells counts, between IFN- $\gamma$ and IL-2 responses in patients are findings consistent with the possibility that the IFN- $\gamma$ and IL-2 responses measured here are being produced by different subsets of $\mathrm{T}$ cells. Thus, we would speculate that some subsets are preferentially induced or maintained at the expense of others in patients undergoing immune restoration after 
HAART. An example of how this might occur can be ascertained from known differential requirements of $\mathrm{CD}^{+}$and $\mathrm{CD}^{+} \mathrm{T}$ cell subsets for IL-7 and IL-15. In general, memory $\mathrm{CD}^{+} \mathrm{T}$ cells appear more dependent on IL15 than IL-7, whereas memory $\mathrm{CD}^{+}{ }^{+} \mathrm{T}$ cells may be more dependent on IL-7 [40, 41]. Consistent with these findings, $\mathrm{CD}^{+}{ }^{+} \mathrm{T}$ cell counts are improved with IL-7 supplementation in humans on HAART [44] and in simian immunodeficiency virus (SIV)-infected and treated macaques, but not with IL-15 therapy in macaques $[45,46]$. The findings of reduced IL-7 producing capacity of lymph node stromal cells associated with fibrosis in the para-cortical $\mathrm{T}$ cell zone [47], as well as improvements with anti-fibrotic therapy [48] contribute to the view that IL-7 may be particularly important in the maintenance of adequate memory $\mathrm{CD}^{+}{ }^{+} \mathrm{T}$ cells or subsets thereof involved in IL-2 production. Deficiency of such cells could lead to suboptimal IL2 production as we have observed here. Alternatively, failure to attain or maintain adequate IL-2 production may also reflect continued high rates of apoptosis of $\mathrm{CD}^{+} \mathrm{T}$ cells or their subsets [24, 25, 49]. Hence, further studies are required to investigate whether IL-7 and other factors are involved in restoration of IL-2 responses of $M$. tuberculosis-specific memory $\mathrm{T}$ cells in HIV infected patients receiving HAART.

Regardless of mechanisms of immune memory restoration or homeostatic maintenance, it is likely that $M$. tuberculosis-specific $\mathrm{T}$ cell production of both IFN- $\gamma$ and IL-2 is important for optimal prevention of reactivation of latent TB infection. The necessity for IFN $-\gamma$ is aptly demonstrated by the increased risk of $\mathrm{TB}$ and other mycobacterial diseases in individuals with genetic defects in the production or action of IFN- $\gamma$ [50], yet IFN- $\gamma$ is clearly not sufficient because most $\mathrm{TB}$ patients readily produce IFN- $\gamma$. IL- 2 promotes the expansion of the antigen specific $\mathrm{T}$ cells and likely play an indispensable role in control of the M. tuberculosis infection [11, 31, 51]. Consistent with the role of IL-2 in proliferation, we confirmed on a subset of the patients in this study that $M$. tuberculosis-specific IL-2 response correlated positively with $\mathrm{CD}_{4}^{+} \mathrm{T}$ cell proliferation ex vivo. The negative correlation of IL-2 production with duration of HAART suggests that proliferative capacity of $M$. tuberculosisspecific $\mathrm{CD}^{+} \mathrm{T}$ cells in HIV-infected patients could be diminished over time after antiretroviral therapy regardless of the gain in $\mathrm{CD}^{+} \mathrm{T}$ cell count. Hence, a failure to maintain adequate levels of $M$. tuberculosis-specific IL-2 secreting cells in patients on long-term HAART, predicts that such patients, despite circulating levels of IFN$\gamma$ producing cells, may be impaired in the development or augmentation of adaptive immune responses to either reactivated latent $\mathrm{TB}$ or new $\mathrm{TB}$ infections.

Despite the evidence of the importance of IL-2 for adequate immune responses, a recent prospective study in
South Africa evaluating the ability of cytokine levels to predict risk of TB observed that TB-specific IL-2 detected in vitro was actually higher among patients who eventually developed disease [52]. This observation is not consistent with what we would have predicted although we did not compare cytokine production in the latent TB infection with active TB in the present study. These findings serve as a reminder that, like IFN- $\gamma$, levels of IL-2 and other cytokines, even if presumed necessary for protection, do not necessarily predict disease. It further underscores the importance of prospective studies to correlate immune responses with actual TB disease.

The cross-sectional approach we have utilized here has the advantage that patients on long-term HAART can be more conveniently recruited and evaluated, but the limitation is that, unlike prospective studies, no baseline values prior to HAART were tested. Thus, we cannot rule out the possibilities that prior to HAART, those patients on long-term HAART had lower levels of IL-2 than those of early HAART subjects, and that either IL2 increased proportionally with IFN- $\gamma$ in the HAART period similarly in both groups, or that IL-2 never changed in the long-term HAART group. In addition to baseline testing, an IL-2 assay of greater sensitivity than the currently available are required since the levels of most participants almost approached the limit of detection. In any case, it is clear that definitive testing of the hypothesis that IL-2 is only transiently increased during the fast redistribution phase of immune reconstitution, but not sustained during the long-term HAART, requires both a prospective study evaluating patients at baseline, and a much longer follow-up period than has previously been employed, and one which, like the aforementioned South African study evaluates disease outcomes.

\section{Conclusion}

In summary, this study has shown an increased antimycobacterial immune response in HIV/latent TB coinfected patients with long-term HAART as evaluated by IFN- $\gamma$ response. However, the failure of $M$. tuberculosis-specific IL-2 responses to improve may indicate that patients on therapy remain only partly competent to mount and augment an effective M. tuberculosis-specific response. This finding is in keeping with the observation that patients on long-term HAART remain at risk, albeit reduced, for new opportunistic infections, and require careful monitoring and follow-up. These findings also call for more prospective studies which evaluate subsets of $\mathrm{T}$ cells in both pre-HAART and over a much longer time period of the therapy to more accurately reveal the immune potential and ability to protect against disease of patients both during the short-term and long-term phases of immune reconstitution. 


\section{Supplementary information}

Supplementary information accompanies this paper at https://doi.org/10. 1186/s12865-019-0317-9

Additional file 1: Figure S1. Correlation of M. tuberculosis antigenspecific IFN- $\gamma$ responses and $\mathrm{CD}^{+}{ }^{+} \mathrm{T}$ cell count. Correlation between frequency IFN- $\gamma$ secreting cells responding to PPD or ESAT- 6 , and the CD4 ${ }^{+} T$ cell count in HAART-naïve $(\mathbf{a}, n=30)$ and HAART-treated $(\mathbf{b}, n=31)$ participants. Spearman correlation was used to calculate correlation coefficients $\left(r_{s}\right)$ and $p$ values.

Additional file 2: Figure S2. Correlation of $M$. tuberculosis antigenspecific $\mathrm{IL}-2$ responses and $\mathrm{CD} 4^{+} \mathrm{T}$ cell count. Correlation between frequency IL-2 secreting cells responding to PPD or ESAT-6, and the CD4 ${ }^{+} \mathrm{T}$ cell count in HAART-naïve $(\mathbf{a}, n=30)$ and HAART-treated $(\mathbf{b}, n=31)$ participants. Spearman correlation was used to calculate correlation coefficients $\left(r_{s}\right)$ and $p$ values

Additional file 3: Figure S3. $C D 4^{+} T$ cell count increased with therapy duration after HAART but not correlated with M. tuberculosis specific IL-2 nor IFN- $\gamma$ responses. (a) $C D 4^{+} T$ cell count before and after HAART in HAART-treated participants $(n=23)$. $p$ value was determined using MannWhitney test. (b) Correlation between the number of increased $\mathrm{CD}^{+} \mathrm{T}$ cells with HAART and duration of therapy. Correlation of the number of $\mathrm{CD}^{+} \mathrm{T}$ cells gained after therapy with PPD and ESAT-6 specific IL-2 (c) and IFN $-\gamma(\mathbf{d})$ responses in HAART-treated participants $(n=23)$. Spearman correlation was used to calculate correlation coefficients $\left(r_{s}\right)$ and $p$ values.

Additional file 4: Figure S4. Association of IL-2 production and T cell proliferation in response to $M$. tuberculosis antigens. Correlation between frequency of IL-2-secreting cells and proliferating T cells among total PBMCs after stimulation with PPD $(n=9)$ and ESAT-6 $(n=10)$. Spearman correlation was used to calculate correlation coefficients $\left(r_{s}\right)$ and $p$ values.

\section{Abbreviations}

AHRI: Armauer Hansen Research Institute; AID: Autoimmun Diagnostika; BCG: Bacille Calmette-Guérin; CD: Cluster of differentiation;

CSFE: Carboxyfluorescein diacetate succinimidyl ester; DMSO: Dimethyl sulfoxide; ELISPOT: Enzyme-linked immunospot; ESAT-6: Early secreted antigen-6; FBS: Fetal Bovine Serum; HAART: Highly active anti-retroviral therapy; HIV: Human immunodeficiency virus; IFN: Interferon; IL: interleukin; IQR: Interquartile range; M. tuberculosis: Mycobacterium tuberculosis; PBMC: Peripheral blood mononuclear cell; PHA: Phytohemagglutinin; PPD: Purified protein derivative; SFC: Spot forming cell; SIV: Simian immunodeficiency virus; SSI: Statens Serum Institute; TB: Tuberculosis; TNF: Tumor necrosis factor; TST: Tuberculin skin test

\section{Acknowledgments}

We acknowledge Dr. Semira Eshetu, staff clinicians and laboratory technologists of the ALERT hospital for their tireless support during patient recruitment, sample collection and performing CD4 ${ }^{+}$T cell counts; Armauer Hansen Research Institute (AHRI) for the financial and material support; and clinical nurses of AHRI: S/r Genet Amare and S/r Haregewine Yetesha for performing the tuberculin skin tests. The authors would like to thank all study participants who volunteered to participate in this study. We are also grateful to Statens Serum Institut (SSI) for providing us with the ESAT-6 peptides used in this study.

\section{Authors' contributions}

GD performed the immunoassays, analyzed and interpreted the data and wrote the manuscript. $\mathrm{RH}$ designed the study and made substantial contribution to the data interpretation and revision of the manuscript. DG contributed to the immunoassays, data analysis and revision of the manuscript. AT and AA contributed to the study design, data interpretation and revision of the manuscript. All authors read and approved the final manuscript.

\section{Funding}

No special funding was received for this study. The study was financially supported by the AHRI core budget. AHRI funding sources had no role in the study design, conduct and outcome of the manuscript.

\section{Availability of data and materials}

The datasets used and/or analyzed during the current study are available from the corresponding author on reasonable request.

\section{Ethics approval and consent to participate}

This study was reviewed and approved by Research Ethical Review Committee at Department of Medical Laboratory Science, Addis Ababa University, AHRI/ ALERT Ethics Review committee and the Ethiopian National Research Ethical Review Committee. The purpose of the study, type and amount of specimen needed were explained to the participants and written informed consent was obtained from all study participants recruited in this study.

\section{Consent for publication}

Not applicable.

\section{Competing interests}

The authors declare that they have no competing interests.

\section{Author details}

${ }^{1}$ Armauer Hansen Research Institute, Addis Ababa, Ethiopia. ${ }^{2}$ Department of Medical Laboratory Sciences, Addis Ababa University, Addis Ababa, Ethiopia. ${ }^{3}$ Department of Medical Microbiology and Immunology, Mekelle University, Mekelle, Ethiopia.

\section{Received: 2 November 2018 Accepted: 11 September 2019}

Published online: 11 October 2019

\section{References}

1. World Health Organization (2018). Global tuberculosis report 2018. Geneva, Switzerland. Available at: https://www.who.int/tb/publications/global_report/en/ :

2. Dheda K, Schwander SK, Zhu B, Van ZS, Richard N, ZHANG Y. The immunology of tuberculosis: from bench to bedside. Respirology. 2010; 15(3):433-50.

3. Ellner JJ. The immune response in human tuberculosis: implications for tuberculosis control. J Infect Dis. 1997;176(5):1351-9.

4. Houben RM, Dodd PJ. The global burden of latent tuberculosis infection: a reestimation using mathematical modelling. PLoS Med. 2016:13(10):e1002152.

5. Cooper AM. Cell-mediated immune responses in tuberculosis. Annu Rev Immunol. 2009;27:393-422

6. Zhang Q, Sugawara I. Immunology of tuberculosis. World journal of experimental medicine. 2012;2(4):70.

7. Bozzano F, Marras F, De Maria A. Immunology of tuberculosis. Mediterranean journal of hematology and infectious diseases. 2014;6(1)

8. Comstock GW, LIVESAY VT, WOOLPERT SF. The prognosis of a positive tuberculin reaction in childhood and adolescence. Am J Epidemiol. 1974; 99(2):131-8

9. Corbett EL, Watt CJ, Walker N, Maher D, Williams BG, Raviglione MC, et al. The growing burden of tuberculosis: global trends and interactions with the HIV epidemic. Arch Intern Med. 2003;163(9):1009-21.

10. Nicod LP. Immunology of tuberculosis. Swiss Med Wkly. 2007;137(25-26):357-62.

11. Raja A. Immunology of tuberculosis. Indian J Med Res. 2004;120(4):213

12. Chiacchio T, Petruccioli E, Vanini V, Cuzzi G, La Manna MP, Orlando V, et al. Impact of antiretroviral and tuberculosis therapies on CD4+ and CD8+ HIV/ M. tuberculosis-specific T-cell in co-infected subjects. Immunol Lett. 2018; 198:33-43.

13. Lawn SD, Wood R, De Cock KM, Kranzer K, Lewis JJ, Churchyard GJ. Antiretrovirals and isoniazid preventive therapy in the prevention of HIVassociated tuberculosis in settings with limited health-care resources. Lancet Infect Dis. 2010:10(7):489-98.

14. Lawn SD, Kranzer K, Wood R. Antiretroviral therapy for control of the HIVassociated tuberculosis epidemic in resource-limited settings. Clin Chest Med. 2009;30(4):685-99.

15. Lawn SD, Myer L, Edwards D, Bekker L-G, Wood R. Short-term and long-term risk of tuberculosis associated with CD4 cell recovery during antiretroviral therapy in South Africa. AIDS (London, England). 2009;23(13):1717.

16. Dodd P, Prendergast A, Beecroft C, Kampmann B, Seddon J. The impact of HIV and antiretroviral therapy on TB risk in children: a systematic review and meta-analysis. Thorax. 2017:thoraxjnl-2016-209421.

17. Wendland T, Furrer H, Vernazza PL, Frutig K, Christen A, Matter L, et al. HAART in HIV-infected patients: restoration of antigen-specific CD4 T-cell responses in vitro is correlated with CD4 memory T-cell reconstitution, 
whereas improvement in delayed type hypersensitivity is related to a decrease in viraemia. Aids. 1999;13(14):1857-62.

18. Schluger NW, Perez D, Liu YM. Reconstitution of immune responses to tuberculosis in patients with HIV infection who receive antiretroviral therapy. Chest. 2002;122(2):597-602.

19. Lawn SD, Bekker L-G, Wood R. How effectively does HAART restore immune responses to mycobacterium tuberculosis? Implications for tuberculosis control. Aids. 2005;19(11):1113-24.

20. Foudraine NA, Hovenkamp E, Notermans DW, Meenhorst PL, Klein MR, Lange JM, et al. Immunopathology as a result of highly active antiretroviral therapy in HIV-1-infected patients. Aids. 1999;13(2):177-84.

21. Autran B, Carcelain G, Li TS, Blanc C, Mathez D, Tubiana R, et al. Positive effects of combined antiretroviral therapy on CD4+ T cell homeostasis and function in advanced HIV disease. Science. 1997;277(5322):112-6.

22. Pakker NG, Notermans DW, De Boer RJ, Roos MT, De Wolf F, Hill A, et al. Biphasic kinetics of peripheral blood T cells after triple combination therapy in HIV-1 infection: a composite of redistribution and proliferation. Nat Med. 1998:4(2):208-14.

23. Bucy RP, Hockett RD, Derdeyn CA, Saag MS, Squires K, Sillers M, et al. Initial increase in blood CD4+ lymphocytes after HIV antiretroviral therapy reflects redistribution from lymphoid tissues. J Clin Investig. 1999;103(10):1391.

24. Negredo E, Massanella M, Puig J, Pérez-Álvarez N, Gallego-Escuredo JM, Villarroya J, et al. Nadir CD4 T cell count as predictor and high CD4 T cell intrinsic apoptosis as final mechanism of poor CD4 T cell recovery in virologically suppressed HIV-infected patients: clinical implications. Clin Infect Dis. 2010;50(9):1300-8.

25. Böhler T, Walcher J, Hölzl-Wenig G, Geiss M, Buchholz B, Linde R, et al. Early effects of antiretroviral combination therapy on activation, apoptosis and regeneration of T cells in HIV-1-infected children and adolescents. AIDS. 1999:13(7):779-89.

26. Porsa E, Cheng L, Graviss EA. Comparison of an ESAT-6/CFP-10 peptidebased ELISPOT assay to tuberculin skin test for tuberculosis screening in a moderate risk population. Clinical and Vaccine Immunology. 2007.

27. Kerkhoff AD, Kranzer K, Samandari T, Nakiyingi-Miiro J, Whalen CC, Harries $A D$, et al. Systematic review of TST responses in people living with HIV in under-resourced settings: implications for isoniazid preventive therapy. PLoS One. 2012;7(11):e49928.

28. Millington KA, Innes JA, Hackforth S, Hinks TSC, Deeks JJ, Dosanjh DPS, et al. Dynamic relationship between IFN- $\gamma$ and IL-2 profile of mycobacterium tuberculosis-specific T cells and antigen load. J Immunol. 2007;178(8):5217.

29. Adetifa IM, Ota MO, Walther B, Hammond AS, Lugos MD, Jeffries DJ, et al. Decay kinetics of an interferon gamma release assay with anti-tuberculosis therapy in newly diagnosed tuberculosis cases. PLoS One. 2010;5(9):e12502.

30. Day CL, Mkhwanazi N, Reddy S, Mncube Z, van der Stok M, Klenerman P, et al. Detection of polyfunctional mycobacterium tuberculosis-specific T cells and association with viral load in HIV-1-infected persons. J Infect Dis. 2008;197(7):990-9.

31. Johnson JL, Ssekasanvu E, Okwera A, Mayanja H, Hirsch CS, Nakibali JG, et al. Randomized trial of adjunctive interleukin-2 in adults with pulmonary tuberculosis. Am J Respir Crit Care Med. 2003;168(2):185-91.

32. Gupta A, Wood R, Kaplan R, Bekker L-G, Lawn SD. Tuberculosis incidence rates during 8 years of follow-up of an antiretroviral treatment cohort in South Africa: comparison with rates in the community. PLoS One. 2012;7(3):e34156.

33. Gazzola L, Tincati C, Bellistré GM, d'Arminio Monforte A, Marchetti G. The absence of CD4+ T cell count recovery despite receipt of virologically suppressive highly active antiretroviral therapy: clinical risk, immunological gaps, and therapeutic options. Clin Infect Dis. 2009:48(3):328-37.

34. Gengis EH, Deeks SG. CD4+ T cell recovery with antiretroviral therapy: more than the sum of the parts. The University of Chicago Press; 2009.

35. Wilkinson KA, Seldon R, Meintjes G, Rangaka MX, Hanekom WA, Maartens G, et al. Dissection of regenerating T-cell responses against tuberculosis in HIVinfected adults sensitized by mycobacterium tuberculosis. Am J Respir Crit Care Med. 2009;180(7):674-83.

36. Hengel RL, Allende MC, Dewar RL, Metcalf JA, Mican JM, Lane HC. Increasing CD4+ T cells specific for tuberculosis correlate with improved clinical immunity after highly active antiretroviral therapy. AIDS Res Hum Retrovir. 2002;18(13):969-75.

37. Sutherland JS, Young JM, Peterson KL, Sanneh B, Whittle HC, Rowland-Jones $\mathrm{SL}$, et al. Polyfunctional CD4+ and CD8+ T cell responses to tuberculosis antigens in HIV-1-infected patients before and after anti-retroviral treatment. J Immunol. 2010;184(11):6537-44.
38. Imami N, Antonopoulos C, Hardy GA, Gazzard B, Gotch FM. Assessment of type 1 and type 2 cytokines in HIV type 1-infected individuals: impact of highly active antiretroviral therapy. AIDS Res Hum Retrovir. 1999;15(17):1499-508.

39. Sallusto F, Geginat J, Lanzavecchia A. Central memory and effector memory T cell subsets: function, generation, and maintenance. Annu Rev Immunol. 2004:22:745-63.

40. Surh CD, Sprent J. Homeostasis of naive and memory T cells. Immunity. 2008;29(6):848-62

41. van Leeuwen EM, Sprent J, Surh CD. Generation and maintenance of memory CD4+ T cells. Curr Opin Immunol. 2009;21(2):167-72.

42. Younes S-A, Yassine-Diab B, Dumont AR, Boulassel M-R, Grossman Z, Routy J-P, et al. HIV-1 viremia prevents the establishment of interleukin 2producing HIV-specific memory CD4+ T cells endowed with proliferative capacity. J Exp Med. 2003;198(12):1909-22.

43. Howe R, Dillon S, Rogers L, Palmer B, MaWhinney S, Blyveis N, et al. Phenotypic and functional characterization of HIV-1-specific CD4+ CD8+ double-positive T cells in early and chronic HIV-1 infection. JAIDS J Acquired Immune Defic Syndromes. 2009;50(5):444-56.

44. Levy Y, Lacabaratz C, Weiss L, Viard J-P, Goujard C, Lelièvre J-D, et al. Enhanced T cell recovery in HIV-1-infected adults through IL-7 treatment. J Clin Invest. 2009;119(4):997.

45. Leone A, Rohankhedkar M, Okoye A, Legasse A, Axthelm MK, Villinger F, et al. Increased CD4+ T cell levels during IL-7 administration of antiretrovira therapy-treated simian immunodeficiency virus-positive macaques are not dependent on strong proliferative responses. J Immunol. 2010;185(3):1650-9.

46. Lugli E, Mueller YM, Lewis MG, Villinger F, Katsikis PD, Roederer M. IL-15 delays suppression and fails to promote immune reconstitution in virally suppressed chronically SIV-infected macaques. Blood. 2011;118(9):2520-9.

47. Zeng M, Southern PJ, Reilly CS, Beilman GJ, Chipman JG, Schacker TW, et al. Lymphoid tissue damage in HIV-1 infection depletes naive T cells and limits T cell reconstitution after antiretroviral therapy. PLoS Pathog. 2012;8(1):e1002437.

48. Estes J, Reilly C, Trubey C, Fletcher C, Cory T, Piatak M Jr. Antifibrotic therapy in SIV infection preserves CD4 T cell populations and improves immune reconstitution with antiretroviral therapy. J Infect Dis. 2015;211:744-54.

49. Torti C, Cologni G, Uccelli MC, Quiros-Roldan E, Imberti L, Airó P, et al. Immune correlates of virological response in HIV-positive patients after highly active antiretroviral therapy (HAART). Viral Immunol. 2004:17(2):279-86.

50. Ottenhoff TH, Kumararatne D, Casanova J-L. Novel human immunodeficiencies reveal the essential role of type-1 cytokines in immunity to intracellular bacteria. Immunol Today. 1998;19(11):491-4.

51. Ganusov W, Milutinovic D, De Boer RJ. IL-2 regulates expansion of CD4+ T cell populations by affecting cell death: insights from modeling CFSE data. J Immunol. 2007;179(2):950-7.

52. Lesosky M, Rangaka MX, Pienaar C, Coussens AK, Goliath R, Mathee S, et al. Plasma biomarkers to detect prevalent, or predict progressive, HIV-1associated tuberculosis. Clin Infect Dis. 2018.

\section{Publisher's Note}

Springer Nature remains neutral with regard to jurisdictional claims in published maps and institutional affiliations.

Ready to submit your research? Choose BMC and benefit from:

- fast, convenient online submission

- thorough peer review by experienced researchers in your field

- rapid publication on acceptance

- support for research data, including large and complex data types

- gold Open Access which fosters wider collaboration and increased citations

- maximum visibility for your research: over $100 \mathrm{M}$ website views per year

At $\mathrm{BMC}$, research is always in progress.

Learn more biomedcentral.com/submissions 